\title{
Systematic review of noninvasive positive pressure ventilation in severe stable COPD
}

\author{
M.A. Kolodziej*, L. Jensen ${ }^{\#}$, B. Rowe ${ }^{\star}$ and D. Sin ${ }^{+}$
}

ABSTRACT: The present systematic review examined the effectiveness of bilevel noninvasive positive pressure ventilation (NIPPV) in the management of chronic respiratory failure (CRF) due to severe stable chronic obstructive pulmonary disease (COPD).

Randomised controlled trials (RCTs) and non-RCTs (crossover design) of adults with severe stable COPD and CRF receiving bilevel NIPPV via nasal, oronasal or total face mask were identified from electronic databases and manual screening of journals and reference lists.

Respiratory function (gas exchange, lung function, ventilatory/breathing pattern, respiratory muscle function and work of breathing) and health-related outcomes (dyspnoea, functional status, exercise tolerance, health-related quality of life (HRQOL), morbidity and mortality) were assessed.

In total, 15 studies met the inclusion criteria: six RCTs and nine non-RCTs. RCTs did not find improved gas exchange with bilevel NIPPV, while non-RCTs did. Lung hyperinflation and diaphragmatic work of breathing were reduced in a nonrandomised subset. HRQOL and dyspnoea, the least studied outcomes, showed improvement with bilevel NIPPV.

In a subset of individuals on maximal medical treatment regimes for severe stable chronic obstructive pulmonary disease, bilevel noninvasive positive pressure ventilation may have an adjunctive role in the management of chronic respiratory failure through attenuation of compromised respiratory function and improvement in health-related outcomes.

KEYWORDS: Chronic obstructive pulmonary disease, chronic respiratory failure, noninvasive positive pressure ventilation, systematic review

hronic respiratory failure $(\mathrm{CRF})$ due to chronic obstructive pulmonary disease (COPD) contributes a significant social and economic burden to individuals, families and the healthcare system. The incidence of COPD, in terms of its combined mortality and disability, was the 12th highest for diseases worldwide in 1990 and is expected to become the fifth highest by 2020 , with mortality expected to increase fivefold by 2015 [1-3]. The rate of progression, the extent of airflow obstruction and airway hyperreactivity, and the impairment in alveolar ventilation and gas exchange contribute to the heterogeneity of COPD and the extent of chronic bronchitic versus emphysematous change that occurs. Reduced alveolar ventilation in CRF due to COPD results in nocturnal and daytime gas exchange abnormalities, sleep-disordered breathing, dyspnoea and increased work of breathing, which in turn lead to significant functional impairment, morbidity and mortality [4]. The eventual development of CRF is characterised by varying degrees of ventilation-perfusion mismatch, hypoxia and hypercapnia [5]. Reduced respiratory reserve associated with ongoing morbidity renders COPD patients at risk of acute respiratory decompensation [6, 7]. Symptom management and prevention of respiratory decompensation are important in reducing morbidity and mortality associated with COPD.

The use of bilevel noninvasive positive pressure ventilation (NIPPV) in acute respiratory failure due to COPD exacerbation has been shown to reduce the need for intubation and mechanical ventilation, the length of hospital stay and mortality [4, 8-10]. However, evidence to support the use of bilevel NIPPV in CRF in the setting of severe stable COPD has been inconsistent [11-13], and is primarily based on gas exchange and lung function rather than health-related outcomes such as dyspnoea, symptom relief, functional status, frequency of exacerbations and health-related quality of life (HRQOL). Furthermore, existing systematic reviews on the management of CRF due to severe stable COPD are not specific to bilevel NIPPV [14, 15].

The present systematic review was undertaken to critically appraise and summarise studies examining bilevel NIPPV in the management of CRF in

\section{AFFILIATIONS}

Depts of *Pulmonary Medicine, and

'Emergency Medicine, Faculty of

Medicine and Dentistry, University of Alberta Hospitals, and

${ }^{\text {\#} F a c u l t y ~ o f ~ N u r s i n g, ~ U n i v e r s i t y ~ o f ~}$ Alberta, Edmonton, $A B$, and ${ }^{+}$Division of Internal Medicine, St. Paul's Hospital, Vancouver, BC, Canada.

\section{CORRESPONDENCE}

L. Jensen

Faculty of Nursing University of Alberta

Edmonton

AB T6G 2G3

Canada

Fax: 17804922551

E-mail: Iouise.jensen@ualberta.ca

Received:

November 062006

Accepted after revision:

April 142007

STATEMENT OF INTEREST

None declared 


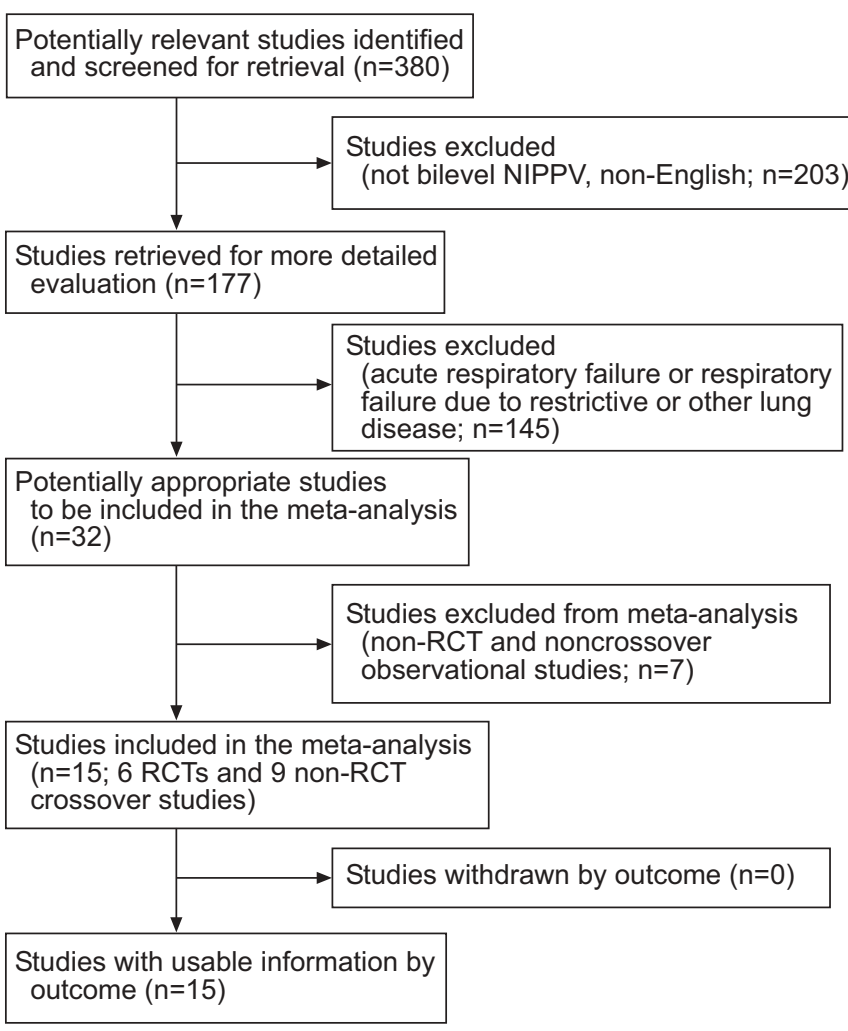

FIGURE 1. Flow diagram of included/excluded studies. NIPPV: noninvasive positive pressure ventilation; RCT: randomised controlled trial.

severe stable COPD. The effectiveness of bilevel NIPPV in slowing the progression of worsening gas exchange and managing distressing symptoms (e.g. dyspnoea, work of breathing and exercise tolerance) was assessed. The nature and extent of bilevel NIPPV that rendered disease-related morbidity more manageable was also examined. Finally, whether there is a difference in the nature and extent of the response to bilevel NIPPV use in different subsets of COPD patients with CRF was explored.

\section{METHODS}

\section{Studies included}

Randomised controlled trials (RCTs) and non-RCTs (withinsubject crossover design) involving COPD patients who received bilevel NIPPV via nasal, oronasal and/or total face mask interfaces to manage symptoms associated with worsening CRF with post-intervention follow-up of less than, as well as greater than, 3 months, were included.

\section{Study participants}

Patients included were adults ( $\geqslant 18$ yrs old) with CRF due to COPD (chronic bronchitis and emphysema). Studies with patients who were predominantly asthmatic and/or had reversibility of airflow obstruction, according to pulmonary function, were excluded. CRF was defined by the physiological changes compatible with underlying COPD, arterial blood gases, declining lung function, symptoms of chronic hypoventilation, increased work of breathing, dyspnoea and reduced exercise tolerance.

\section{Study outcome measures}

The primary outcome was respiratory function as assessed by: 1) gas exchange (arterial blood gases, arterial oxygen saturation and transcutaneous carbon dioxide tension $\left.\left(P_{\mathrm{tc}}, \mathrm{CO}_{2}\right)\right)$, 2) lung function (forced expiratory volume in one second $(\mathrm{FEV} 1)$ ); 3) ventilatory/breathing pattern (minute ventilation $\left(V^{\prime} \mathrm{E}\right)$, tidal volume $(V \mathrm{~T})$ and $V \mathrm{~T} /$ inspiratory time (tI) ratio); and

TABLE 1 Bilevel noninvasive positive pressure ventilation in chronic obstructive pulmonary disease: study characteristics

\begin{tabular}{|c|c|c|c|c|c|c|}
\hline First author [Ref.] & Study design & Length & Enrolled & Randomised & Completed & Concealed randomisation \\
\hline \multicolumn{7}{|l|}{ RCTs } \\
\hline DIAZ [19] & $B S, B A$ & 3 weeks & 56 & 36 & 36 & Yes \\
\hline RENSTON [22] & $\mathrm{BS}, \mathrm{BA}$ & $<1$ week & 17 & 17 & 17 & Yes \\
\hline CASANOVa [11] & BS, RM & $1 \mathrm{yr}$ & 80 & 52 & 44 & Yes \\
\hline CLINI [23] & $\mathrm{BS}, \mathrm{RM}$ & $2 \mathrm{yrs}$ & 122 & 86 & 47 & No \\
\hline \multicolumn{7}{|l|}{ Non-RCTs } \\
\hline AMBROSINO [25] & CSVR, WS, RM & $<1$ week & 7 & 7 & 7 & \\
\hline HIGHCOCK [18] & CSVR, WS, RM & $<1$ week & 8 & 8 & 8 & \\
\hline KRACHMAN [20] & CSVR, WS, BA & $<1$ week & 6 & 6 & 6 & \\
\hline LIEN [26] & CSVR, WS, RM & $<1$ week & 11 & 11 & 11 & \\
\hline LIN [27] & CSVR, WS, RM & 6 weeks & 17 & 12 & 10 & \\
\hline
\end{tabular}

Data are presented as $\mathrm{n}$. All randomised controlled trials (RCTs) were single blind. All non-RCTs included random order assignment and statistical control of confounders. BS: between subjects; BA: before/after; RM: repeated measures; CSVR: crossover; WS: within subjects. 


\begin{tabular}{|c|c|c|c|c|c|c|c|}
\hline TABLE 2 & \multicolumn{7}{|c|}{$\begin{array}{l}\text { Combined analysis for arterial oxygen tension in chronic obstructive pulmonary disease randomised controlled trials } \\
\text { (RCTs) }\end{array}$} \\
\hline \multirow{2}{*}{\multicolumn{2}{|c|}{ First author [Ref.] }} & \multicolumn{2}{|c|}{ Bilevel NIPPV } & \multicolumn{2}{|c|}{ Control } & \multirow[t]{2}{*}{ Weight \% } & \multirow[t]{2}{*}{ WMD (random) $95 \% \mathrm{Cl}$} \\
\hline & & $\mathbf{n}$ & Mean \pm SD & $\mathbf{n}$ & Mean \pm SD & & \\
\hline \multicolumn{2}{|c|}{ Casanova [11] } & 20 & $56.30 \pm 8.20$ & 24 & $57.30 \pm 6.50$ & 24.80 & $-1.00(-5.44-3.44)$ \\
\hline \multicolumn{2}{|l|}{ DIAZ [19] } & 18 & $53.77 \pm 7.95$ & 18 & $50.47 \pm 6.00$ & 23.37 & $3.30(-1.30-7.90)$ \\
\hline \multicolumn{2}{|l|}{ GARROD [24] } & 17 & $66.10 \pm 8.55$ & 20 & $66.80 \pm 9.38$ & 15.86 & $-0.70(-6.48-5.08)$ \\
\hline \multicolumn{2}{|l|}{$\mathrm{G}_{A Y}[21]$} & 4 & $70.50 \pm 4.70$ & 6 & $60.30 \pm 14.40$ & 3.81 & $10.20(-2.21-22.61)$ \\
\hline \multicolumn{2}{|l|}{ Renston [22] } & 9 & $66.00 \pm 15.00$ & 8 & $67.00 \pm 8.48$ & 4.47 & $-1.00(-12.43-10.43)$ \\
\hline \multicolumn{2}{|l|}{ Total } & 91 & & 100 & & 100 & $1.86(-0.60-4.32)$ \\
\hline
\end{tabular}

NIPPV: noninvasive positive pressure ventilation; WMD: weighted mean difference; Cl: confidence interval. Comparison: RCT trials of bilevel NIPPV versus all modalities (long-term oxygen therapy, sham ventilation, exercise). Outcome: arterial oxygen tension $\mathrm{cmH}_{2} \mathrm{O}$. Test for heterogeneity: $\mathrm{Chi}$ squared $=5.73, \mathrm{df}=5(\mathrm{p}=0.33), \mathrm{I}^{2}=12.7 \%$. Test for overall effect: $Z=1.49(p=0.14)$.

4) respiratory muscle function/work of breathing (maximal inspiratory mouth pressure (MIP), maximal expiratory mouth pressure (MEP), diaphragmatic electromyogram (EMGdi), electromyogram of sternocleidomastoid muscle (EMGst), dynamic intrinsic positive end-expiratory pressure (PEEPi,dyn), diaphragmatic pressure $(P \mathrm{di})$, maximal inspiratory pressure $(P \mathrm{I}, \max )$ and maximal expiratory pressure $(P \mathrm{E}, \mathrm{max}))$.

Health-related outcomes, or secondary outcomes, included: 1) symptom relief (dyspnoea); 2) functional status (bilevel positive airway pressure (BiPAP) Functional Impairment Scale, London Chest Activity of Daily Living Scale, modified Medical Research Council Dyspnoea Scale (MRCD) and Oxygen Cost Diagram); 3) exercise tolerance (6-min walk test (6MWT) and shuttle walking test (SWT)); 4) HRQOL (Chronic Respiratory Disease Questionnaire (CRDQ), Maugeri Foundation Respiratory Failure Questionnaire (MRF-28), Short-Form

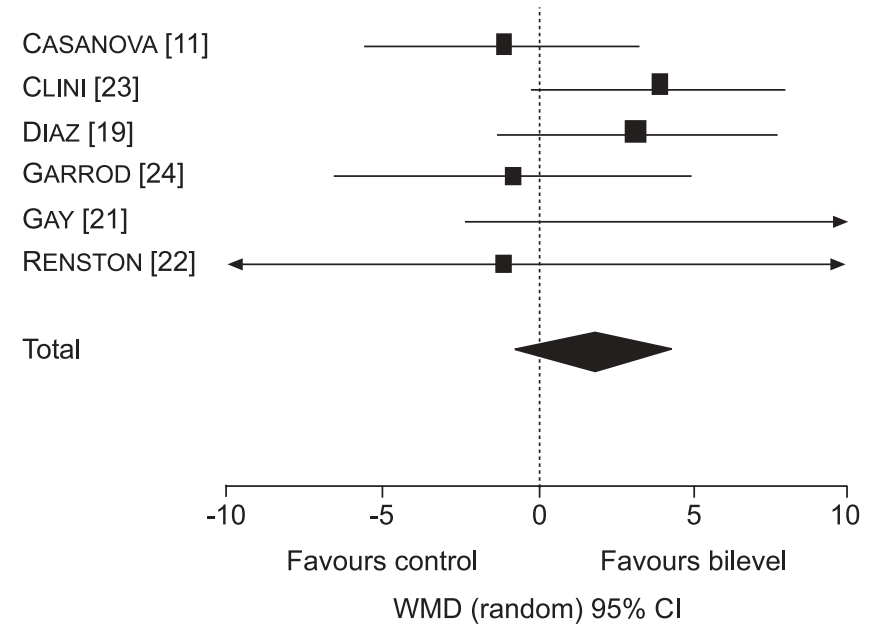

FIGURE 2. Combined analysis for arterial oxygen tension in chronic obstructive pulmonary disease randomised controlled trials (RCTs). Comparison: $\mathrm{RCT}$ trials of bilevel noninvasive positive pressure ventilation versus all modalities (long-term oxygen therapy, sham ventilation, exercise). Outcome: arterial oxygen tension $\mathrm{cmH}_{2} \mathrm{O}$. WMD: weighted mean difference; $\mathrm{Cl}$ : confidence interval.
Questionnaire (SF-36) and St George's Respiratory Questionnaire (SGRQ)); 5) morbidity (hospital admissions, intensive care unit (ICU) admissions and hospital length of stay); 6) mortality (survival estimates); and 7) comfort/compliance.

\section{Search and selection of studies}

Search terms employed were "bilevel", "bilevel airway pressure OR bilevel CPAP OR biphasic positive airway pressure", as well as "nasal ventilation OR positive pressure ventilation OR NIPPV". Electronic databases searched included MEDLINE, preMEDLINE, EMBASE, CINAHL, Conference Papers Index, Online Computer Library Centre, Inc., Papers First (Conference Papers), Cochrane Library (including Cochrane Database of Systematic Reviews, DARE and Cochrane Controlled Trials), American College of Physicians Journal Club, PubMed, Biological Abstracts, and Dissertation Abstracts for the years 2001-2003. The following journals were hand searched for the years 2001-2003: American Journal of Respiratory and Critical Care Medicine, Chest, European Respiratory Journal, Lung, The New England Journal of Medicine and Thorax. Reference lists of all articles identified for inclusion were manually screened to identify any additional studies. Only studies reported in English were included. Titles and abstracts (when available) of all published reports identified through the electronic search were scanned independently by two reviewers. Full reports were then obtained and assessed independently by the two reviewers to establish whether studies met the inclusion criteria. Disagreements were resolved by consensus.

\section{Quality assessment of studies}

Quality assessment of all included studies was undertaken independently by the two reviewers. The quality criteria examined for followed the RCT and non-RCT validity tools developed by ESTABROOKS et al. [16], which included design allocation, recruitment, inclusion and exclusion criteria, follow-up, control of confounders, description of intervention, data collection, outcome measurement and statistical analysis. The methodological quality of studies was then estimated as low, medium or high. 


\begin{tabular}{|c|c|c|c|c|c|c|}
\hline \multirow[t]{2}{*}{ First author [Ref.] } & \multicolumn{2}{|c|}{ Bilevel NIPPV } & \multicolumn{2}{|c|}{ Control } & \multirow[t]{2}{*}{ Weight \% } & \multirow[t]{2}{*}{ WMD (random) $95 \% \mathrm{Cl}$} \\
\hline & $\mathbf{n}$ & Mean \pm SD & $\mathbf{n}$ & Mean \pm SD & & \\
\hline Casanova [11] & 20 & $51.10 \pm 8.80$ & 24 & $52.30 \pm 6.10$ & 18.77 & $-1.20(-5.76-3.36)$ \\
\hline GARROD [24] & 17 & $43.30 \pm 6.68$ & 20 & $44.20 \pm 9.07$ & 17.64 & $-0.90(-5.99-4.19)$ \\
\hline GAY $[21]$ & 4 & $57.50 \pm 14.40$ & 6 & $50.20 \pm 4.30$ & 5.50 & $7.30(-7.23-21.83)$ \\
\hline Renston [22] & 9 & $52.00 \pm 9.00$ & 8 & $44.00 \pm 4.24$ & 14.62 & $8.00(1.43-14.57)$ \\
\hline Total & 91 & & 100 & & 100 & $-1.20(-5.05-2.65)$ \\
\hline
\end{tabular}

NIPPV: noninvasive positive pressure ventilation; WMD: weighted mean difference; $\mathrm{Cl}$ confidence interval. Comparison: RCT trials of bilevel NIPPV versus all modalities (Iong-term oxygen therapy, sham ventilation, exercise). Outcome: arterial carbon dioxide tension $\mathrm{cmH}_{2} \mathrm{O}$. Test for heterogeneity: $\mathrm{Chi}$ squared $=18.76$, $\mathrm{df}=5$ ( $p=0.002$ ), $\mathrm{I}^{2}=73.3 \%$. Test for overall effect: $Z=0.61(p=0.54)$.

\section{Data analysis}

Data were analysed first by assessing for heterogeneity in study quality, patients, interventions, and measurement of outcomes to determine the appropriateness of pooling data. A random effects model was used, with $p<0.05$ considered statistically significant. For meta-analysis of RCTs, weighted mean differences (WMD) and 95\% confidence intervals (CI) were calculated for the following comparisons: 1) RCTs of bilevel NIPPV intervention versus all modalities (long-term oxygen therapy (LTOT), sham ventilation and exercise); and 2) RCTs of bilevel NIPPV intervention versus all modalities by length of trial, with subgroup analysis for trials $\leqslant 8$ weeks or $>8$ weeks. Meta-analysis for non-RCTs was also carried out, comparing bilevel NIPPV intervention versus all modalities (LTOT, sham ventilation, exercise). Meta-analysis for nonRCTs required first calculating the mean difference (MD) and

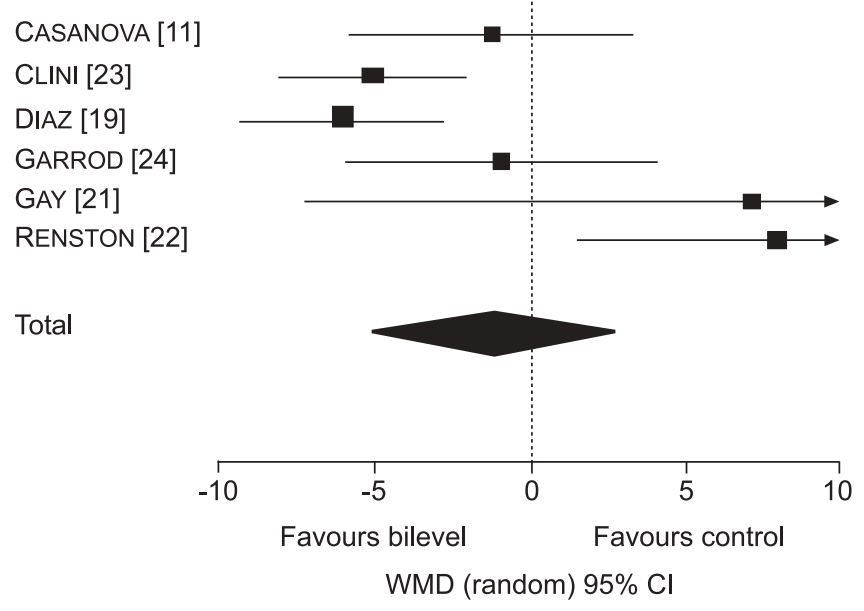

FIGURE 3. Combined analysis for arterial carbon dioxide tension in chronic obstructive pulmonary disease randomised controlled trials (RCTs). Comparison: RCT trials of bilevel noninvasive positive pressure ventilation versus all modalities (long-term oxygen therapy, sham ventilation, exercise). Outcome: arterial carbon dioxide tension $\mathrm{CmH}_{2} \mathrm{O}$. WMD: weighted mean difference; $\mathrm{Cl}$ : confidence interval. standard error for each study outcome, following which the generic inverse variance outcome was used to calculate the mean difference (rather than the WMD). Subgroup analyses were not done for non-RCTs. Treatment effects were pooled using a random effects model, which takes into consideration variation of study differences in underlying effect, and were reported as MD with $95 \%$ CIs.

\section{RESULTS}

\section{Description of the included studies}

Study designs

From 177 publications retrieved, 55 studies were screened for inclusion. In total, 15 studies met the inclusion criteria: six RCTs and nine non-RCTs (fig. 1). Out of the 15 studies, 11 included a run-in, or acclimatisation period, which varied in length from $2 \mathrm{~h}$ to 1 month and 10 days.

\section{Study participants}

Study patients were chronically dyspnoeic and had severe obstructive lung disease, with a baseline FEV1 $<1$ L and FEV1/ forced vital capacity ratio $<50 \%$ predicted. The majority of studies included patients with arterial carbon dioxide tension $\left(P a, \mathrm{CO}_{2}\right)>6.7 \mathrm{kPa}(>50 \mathrm{mmHg})$. Patients had a mean (range) age of 63 (44-74) yrs and were predominantly male. The sample size was $<50$ in all but two studies. The total sample consisted of 466 patients.

\section{Study length of follow-up}

Length of follow-up for the six RCTs varied from 5 days to 2 yrs. Three RCTs included a follow-up of $\leqslant 8$ weeks and three RCTs had included follow-up for $>8$ weeks. Six of the nine non-RCTs were short daytime trials of 1-3 days, while the remaining three studies were longer nocturnal trials (6 weeks, 3 and 6 months).

\section{Study comparisons}

Study comparisons included bilevel NIPPV versus spontaneous breathing, sham ventilatilation, LTOT, exercise and other types of ventilation (i.e. volume ventilation, different bilevel NIPPV pressure settings, different bilevel NIPPV ventilators). 


\begin{tabular}{|c|c|c|c|c|c|}
\hline TABLE 4 & $\mathrm{~d}$ analysis for ar & rial oxygen tensic & chronic obstruct & nary dise & ndomised controlled \\
\hline First author [Ref.] & Favours bilevel $\mathbf{n}$ & Favours control $n$ & $\mathrm{MD} \pm \mathrm{SE}$ & Weight \% & MD (random) 95\% Cl \\
\hline AmBrosino [25] & 7 & 7 & $5.0000 \pm 2.4201$ & 18.22 & $5.00(0.26-9.74)$ \\
\hline KRACHMAN [20] & 6 & 6 & $3.6500 \pm 10.0177$ & 2.26 & $3.65(-15.98-23.28)$ \\
\hline LIN [27] & 10 & 12 & $0.3000 \pm 1.3508$ & 26.08 & $0.30(-2.35-2.95)$ \\
\hline MARAGONI [28] & 14 & 14 & $13.2000 \pm 4.3177$ & 9.32 & $13.20(4.74-21.66)$ \\
\hline Meecham Jones [29] & 14 & 14 & $5.9000 \pm 2.7030$ & 16.44 & $5.90(0.60-11.20)$ \\
\hline Nava $[17]$ & 6 & 7 & $5.1000 \pm 1.9522$ & 21.51 & $5.10(1.27-8.93)$ \\
\hline StRUMPF [30] & 7 & 7 & $2.0000 \pm 5.6552$ & 6.17 & $2.00(-9.08-13.08)$ \\
\hline Total & 64 & 67 & & 100 & $4.49(1.43-7.55)$ \\
\hline
\end{tabular}

MD: mean difference; Cl: confidence interval. Comparison: crossover trials of bilevel noninvasive positive pressure ventilation versus all modalities. Outcome: arterial oxygen tension $\mathrm{mmHg}$. Test for heterogeneity: Chi squared $=12.51, d f=6(p=0.05), \mathrm{I}^{2}=52.0 \%$. Test for overall effect: $Z=2.88(p=0.004)$.

\section{Study interventions}

All studies used a Respironics (Murrysville, PA, USA) BiPAP for the NIPPV intervention except NAVA et al. [17], who used a BIRD (Palm Springs, CA, USA) pressure support ventilation (PSV) ventilator, and HiGHCOCK et al. [18], who compared three types of bilevel NIPPV (BiPAP Respironics ST 30 (Respironics), Nippy2 (B+D Electrical Ltd, Stratford upon Avon, UK) and VPAP II ST (Resmed Ltd, Abingdon, UK) models). In half of the studies that used BiPAP Respironics, the spontaneous (ST) mode was used, while the remaining studies used the spontaneous (S) mode. Inspiratory positive airway pressures (IPAP) ranged from $<0.98 \mathrm{kPa}\left(<10 \mathrm{cmH}_{2} \mathrm{O}\right)$ in two studies, $0.98-2.0 \mathrm{kPa}\left(10-20 \mathrm{cmH}_{2} \mathrm{O}\right)$ in the majority and $>2.0 \mathrm{kPa}$ $\left(>20 \mathrm{cmH}_{2} \mathrm{O}\right)$ in one third of the studies. Expiratory positive airway pressures (EPAP) were $\leqslant 0.49 \mathrm{kPa}\left(\leqslant 5 \mathrm{cmH}_{2} \mathrm{O}\right)$ in all studies. A nasal interface was predominantly used, except by DiAz et al. [19], who used an oronasal interface, and KRACHMAN et al. [20], who used nasal, oronasal or total face masks.

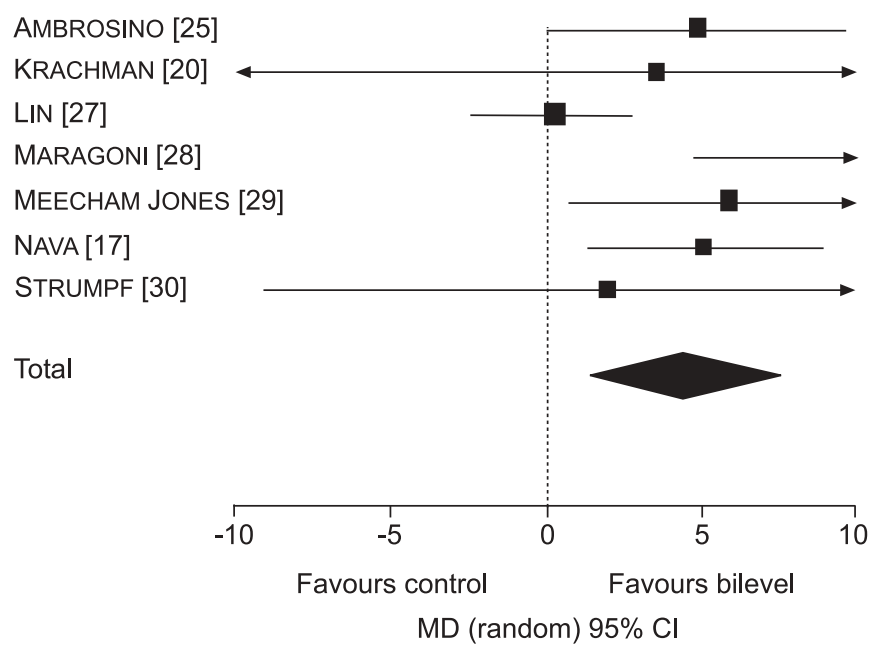

FIGURE 4. Combined analysis for arterial oxygen tension in chronic obstructive pulmonary disease nonrandomised controlled trials. Comparison: crossover trials of bilevel noninvasive positive pressure ventilation versus all modalities. Outcome: arterial oxygen tension mmHg. MD: mean difference; $\mathrm{Cl}$ : confidence interval.

\section{Methodological quality}

Blinding of randomisation was evident in four out of six RCTs. All were single blind with respect to interventions. The majority of non-RCTs used repeated measures (seven out of nine studies), while two used before/after measures (table 1). All studies included random assignment and attempted, statistically, to control for confounders. The majority of studies were rated high on methodological quality.

\section{Respiratory function}

Gas exchange

Combined analysis for RCTs found no improvement in arterial oxygen tension $\left(\mathrm{Pa}_{\mathrm{a}} \mathrm{O}_{2} ; \mathrm{WMD} 1.86,95 \% \mathrm{CI}-0.60-4.32 \mathrm{mmHg}\right)$ and $\mathrm{Pa}, \mathrm{CO}_{2}$ (WMD $-1.20,95 \% \mathrm{CI}-5.05-2.65 \mathrm{mmHg}$ ) with bilevel NIPPV (tables 2 and 3; figs 2 and 3). Meta-analysis of seven non-RCTs found an increase in $\mathrm{Pa}, \mathrm{O}_{2}$ with bilevel NIPPV (MD $4.49,95 \%$ CI $1.43-7.55 \mathrm{mmHg} ; \mathrm{p}=0.004$; table 4 and fig. 4) [17, 20, 25, 27-30]. Eight non-RCTs favoured bilevel NIPPV for $\mathrm{Pa}_{\mathrm{a}} \mathrm{CO}_{2}$ reduction (MD -3.52, 95\% CI -5.93-1.11 mmHg; table 5 and fig. 5) [17, 20, 25-30]. However, heterogeneity was evident $(p=0.13)$. Subgroup analysis of RCTs showed no evidence for improved gas exchange according to trial length $(\leqslant 8$ weeks or $>8$ weeks).

\section{Lung function}

There was no evidence to support improvement of FEV1 with bilevel NIPPV in either RCTs or non-RCTs. One of the two RCTs that included residual volume (RV) as an assessment of dynamic hyperinflation reported a reduction in RV from $201 \pm 48 \%$ pred to $165 \pm 49 \%$ pred following 3 weeks of bilevel NIPPV $(p<0.001)[19]$.

\section{Ventilatory/breathing pattern}

Only one RCT [19] assessed changes in breathing pattern and found increases in $V^{\prime} \mathrm{E}\left(1.16 \mathrm{~L} \cdot \mathrm{min}^{-1}\right.$ increase; $\left.\mathrm{p}<0.05\right), V \mathrm{~T}$ $(181 \mathrm{~mL}$ increase; $\mathrm{p}<0.001)$ and total time of respiratory cycle $(0.67 \mathrm{~s}$ increase; $\mathrm{p}<0.01)$ during bilevel ventilation, which were associated with reduced $\mathrm{RV}$, total lung capacity and PEEPi,dyn. Meta-analysis of five non-RCTs [17, 18, 26-27] that assessed ventilatory/breathing pattern parameters with bilevel NIPPV showed an increase in VT (MD $195.64 \mathrm{~mL}, 95 \%$ CI $21.97-$ $369.31 \mathrm{~mL} ; \mathrm{p}=0.03$; table 6 and fig. 6). Combined data for four 


\begin{tabular}{|c|c|c|c|c|c|}
\hline TABLE 5 & $\begin{array}{l}\text { ed analysis for a } \\
\text { d trials }\end{array}$ & erial carbon diox & ension in chron & ctive pulm & ase nonrandomised \\
\hline First author [Ref.] & Favours bilevel $\mathbf{n}$ & Favours control $n$ & $\mathrm{MD} \pm \mathrm{SE}$ & Weight \% & MD (random) $95 \% \mathrm{Cl}$ \\
\hline AMBRosino [25] & 7 & 7 & $-7.0000 \pm 3.2071$ & 10.46 & $-7.00(-13.29--0.71)$ \\
\hline KRACHMAN [20] & 6 & 6 & $-3.2700 \pm 3.9438$ & 7.67 & $-3.27(-11.00-4.46)$ \\
\hline LIEN [26] & 11 & 11 & $-0.8000 \pm 4.9179$ & 5.33 & $-0.80(-10.44-8.84)$ \\
\hline MARAGONI [28] & 14 & 14 & $-6.0000 \pm 2.8885$ & 12.08 & $-6.00(-11.66--0.34)$ \\
\hline Meecham Jones [29] & 14 & 14 & $-4.5000 \pm 1.9744$ & 18.72 & $-4.50(-8.37--0.63)$ \\
\hline Nava $[17]$ & 6 & 7 & $-7.7000 \pm 2.7889$ & 12.65 & $-7.70(-13.17--2.23)$ \\
\hline StRUMPF [30] & 7 & 7 & $3.0000 \pm 3.6061$ & 8.80 & $3.00(-4.07-10.07)$ \\
\hline Total & 75 & 78 & & 100 & $-3.52(-5.93--1.11)$ \\
\hline
\end{tabular}

MD: mean difference; $\mathrm{Cl}$ : confidence interval. Comparison: crossover trials of bilevel noninvasive positive pressure ventilation versus all modalities. Outcome: arterial carbon dioxide tension $\mathrm{cmH}_{2} \mathrm{O} /$ end tidal carbon dioxide tension $\mathrm{cmH}_{2} \mathrm{O}$. Test for heterogeneity: Chi squared $=11.16, \mathrm{df}=7(\mathrm{p}=0.13), \mathrm{I}^{2}=37.3 \%$. Test for overall effect: $Z=2.86(p=0.004)$

studies $[17,18,25,26]$ showed an increase in $V \mathrm{~T} / \mathrm{tI}(\mathrm{p}=0.02)$; however, heterogeneity was evident ( $\mathrm{p}=0.45$; table 7 and fig. 7 ). NAVA et al. [17] compared different pressure level settings and showed increases in $V \mathrm{~T} / t$ I on IPAP/EPAP of $10 / 0(0.98 / 0), 20 / 0$ $(2.0 / 0)$ and $20 / 5(2.0 / 0.49)$, but not with the least pressure difference at a setting of $10 / 5 \mathrm{cmH}_{2} \mathrm{O}(0.98 / 0.49 \mathrm{kPa})$.

Respiratory muscle function/work of breathing

Combined analysis of two RCTs with 101 patients [22, 23] found no increase in MIP with bilevel NIPPV (WMD $4.45 \mathrm{cmH}_{2} \mathrm{O}, 95 \% \mathrm{CI}-4.52-13.43 \mathrm{cmH}_{2} \mathrm{O} ; \mathrm{p}=0.33$; table 8 and fig. 8). CASANOVA et al. [11], using a different unit of measure for MIP, also reported no change. Two non-RCTs further failed to show increases in MIP or MEP with bilevel NIPPV [27, 30].

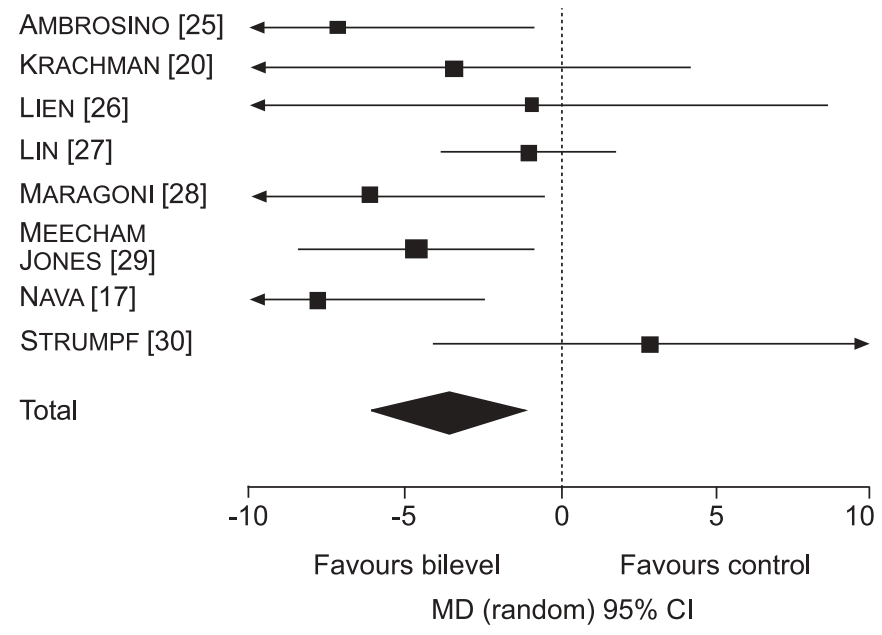

FIGURE 5. Combined analysis for arterial carbon dioxide tension in chronic obstructive pulmonary disease nonrandomised controlled trials. Comparison: crossover trials of bilevel noninvasive positive pressure ventilation versus all modalities. Outcome: arterial carbon dioxide tension $\mathrm{cmH}_{2} \mathrm{O} / \mathrm{end}$ tidal carbon dioxide tension $\mathrm{cmH}_{2} \mathrm{O}$. MD: mean difference; $\mathrm{Cl}$ : confidence interval.
A decrease in Pdi was reported in one non-RCT [17], with all four levels of bilevel NIPPV pressures (IPAP/EPAP of $10 / 0$ (0.98/0), 10/5 (0.98/0.49), 20/0 (2.0/0) and 20/5 $\mathrm{cmH}_{2} \mathrm{O}(2.0 /$ $0.49 \mathrm{kPa})$ ) with seven patients. The study also reported a decrease in PEEPi,dyn with the addition of positive endexpiratory pressure $0.49 \mathrm{kPa}\left(5 \mathrm{cmH}_{2} \mathrm{O}\right)$ to nasal PSV of 0.98 and $2.0 \mathrm{kPa}\left(10\right.$ and $\left.20 \mathrm{cmH}_{2} \mathrm{O}\right)$. The RCT by RENSTON et al. [22] reported a decrease $(66.6 \pm 6 \%)$ in EMGdi with bilevel NIPPV during exercise.

Five out of the nine non-RCTs reported parameters related to respiratory muscle function/work of breathing. AMBROSINO et al. [25] reported no change in EMGdi during bilevel NIPPV. LIEN et al. [26] reported a decrease in EMGst of $-62.93 \pm 23.27 \%$ in four patients with an FEV1 $<0.55 \mathrm{~L}$ after 40 min of bilevel NIPPV, compared with a decrease in EMGst of $-32.45 \pm 42.79 \%$ in seven patients with an FEV1 $>0.55 \mathrm{~L}$, suggesting greater reduction of diaphragmatic activity with bilevel NIPPV in the subset of patients with a lower FEV1. Combined data for PI,max (MD $4.85 \mathrm{cmH}_{2} \mathrm{O}, 95 \%$ CI $0.25-9.44 \mathrm{cmH}_{2} \mathrm{O} ; \mathrm{p}=0.04$ ) and $P$ E,max (MD $4.82 \mathrm{cmH}_{2} \mathrm{O}, 95 \%$ CI $0.56-9.09 \mathrm{cmH}_{2} \mathrm{O} ; \mathrm{p}=0.03$ ) from two non-RCTs $[26,27]$ showed an increase in respiratory muscle strength with bilevel NIPPV, although heterogeneity was evident (table 9 and fig. 9).

\section{Health-related outcomes}

\section{Exercise tolerance}

Three RCTs [21-23] that assessed exercise tolerance using the $6 \mathrm{MWT}$ showed no improvement in the bilevel NIPPV group. The fourth RCT [24] comparing bilevel NIPPV with exercise to exercise alone, demonstrated an increase of $100 \mathrm{~m}(\mathrm{p}<0.001)$ on the SWT in the bilevel NIPPV with exercise group after 8 weeks of bilevel NIPPV. Due to the combined interventions (bilevel NIPPV and exercise), it is not clear whether noninvasive ventilation alone or in combination with exercise contributed to the improvement. Two non-RCTs [18, 29] that assessed exercise tolerance (one using the 6MWT [29] and the other using the SWT [18]) showed no improvement with bilevel NIPPV. 
TABLE 6 Combined analysis for tidal volume $(V T)$ in chronic obstructive pulmonary disease nonrandomised controlled trials

\begin{tabular}{lccccc} 
First author [Ref.] & Favours bilevel $\mathbf{n}$ & Favours control $\mathbf{n}$ & $\mathbf{M D} \pm \mathbf{S E}$ & Weight \% & MD (random) 95\% Cl \\
\hline AMBROSINO [25] & 7 & 7 & $382.0000 \pm 58.2666$ & 21.59 & $382.00(267.80-496.20)$ \\
HIGHCOCK [18] & 8 & 8 & $164.0000 \pm 165.1882$ & 13.03 & $164.00(-159.76-487.76)$ \\
LIEN [26] & 11 & 11 & $50.0000 \pm 54.3557$ & 21.86 & $50.00(-56.54-156.54)$ \\
LIN [27] & 10 & 12 & $23.0000 \pm 13.9401$ & 23.68 & $23.00(-4.32-50.32)$ \\
NAVA [17] & 6 & 7 & $380.0000 \pm 81.1858$ & 19.85 & $380.00(220.88-539.12)$ \\
Total & 42 & 43 & & 100 & $195.64(21.97-369.31)$ \\
\hline
\end{tabular}

MD: mean difference; $\mathrm{Cl}$ : confidence interval. Comparison: crossover trials of bilevel noninvasive positive pressure ventilation versus all modalities. Outcome: $V T \mathrm{~mL}$. Test for heterogeneity: Chi squared=53.19, $d f=4(p<0.00001), I^{2}=92.5 \%$. Test for overall effect: $Z=2.21 \quad(p=0.03)$

\section{Dyspnoea}

Data could not be combined for all RCTs that assessed dyspnoea due to the different measurement scales used. Each RCT demonstrated an improvement in dyspnoea in the bilevel NIPPV group (table 10). RENSTON et al. [22] showed a $66.3 \%$ reduction in dyspnoea in the bilevel NIPPV group $(\mathrm{p}<0.01)$. CASANOVA et al. [11] showed a reduction in dyspnoea at 3 months on two dyspnoea scales $(p=0.035$, MRCD; $p=0.039$, Borg scale) and this improvement was maintained at 6 months on the Borg scale $(p=0.033)$ in the bilevel NIPPV with LTOT group. CLINI et al. [23] used the MRCD to assess dyspnoea in a group of 47 patients and reported a reduction in dyspnoea in the bilevel NIPPV with LTOT group at both $12(\mathrm{p}=0.048)$ and 24 $(p=0.013)$ months. The dyspnoea portion of the CRDQ in the fourth RCT [24] in the bilevel NIPPV and exercise group showed an improvement after 12 weeks $(p<0.05)$. One of two non-RCTs showed no change in dyspnoea as a single outcome [30].

Functional status

Only two RCTs assessed functional status using different measurement scales. RENSTON et al. [22] showed no reduction

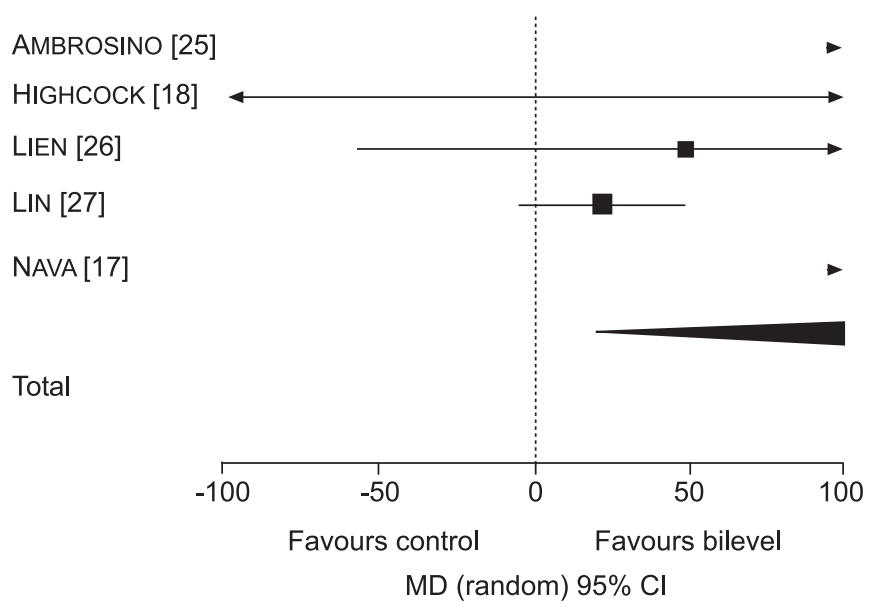

FIGURE 6. Combined analysis for tidal volume (VT) in chronic obstructive pulmonary disease nonrandomised controlled trials. Comparison: crossover trials of bilevel noninvasive positive pressure ventilation versus all modalities. Outcome: $\mathrm{VT} \mathrm{mL}$. MD: mean difference; $\mathrm{Cl}$ : confidence interval. in dyspnoea related to functional impairment with bilevel NIPPV on all scales (modified MRCD, oxygen cost diagram and BiPAP Functional Impairment Scale). The second study by GARROD et al. [24], comparing bilevel NIPPV and exercise to exercise alone reported an improvement in the CRDQ total score from $68.1 \pm 20.9$ to $92.2 \pm 17.0(\mathrm{p}<0.001)$ and $73.3 \pm 22.4$ to $85.1 \pm 23.9(p=0.003)$, respectively; however, there was a greater improvement in all components of the scale (dyspnoea, mastery, emotion and fatigue), as well as the total score for the bilevel NIPPV with exercise group (table 11).

HRQOL

Only one non-RCT [29] reported HRQOL as an outcome measure and showed improved SGRQ scores (total score, $p=0.001$; impact score, $p=0.002$; symptom score, $p=0.007$ ). Using the MRF-28 (which assesses cognitive behaviour, activity, disability and other components), CLINI et al. [23] demonstrated improvement from baseline in the bilevel NIPPV with LTOT group $(p=0.041 ; 95 \%$ CI $0.13-4.07)$ at 24 months. In the study by CLINI et al. [23] there was no significant change in symptoms, activity and impact scores on the SGRQ. As previously mentioned, both the NIPPV with exercise and the exercise only groups in the study by GARROD et al. [24] showed improvement for both the CRDQ total score (difference of 12.3; $p=0.03$ ) and the fatigue component (difference of 3.41 ; $\mathrm{p}=0.01$ ), supporting a significantly greater improvement in the bilevel NIPPV with exercise group compared with the exercise only group (table 12).

\section{Morbidity}

Two RCTs [11, 23] measured morbidity in terms of hospital and ICU admissions. The studies compared bilevel NIPPV and LTOT subjects with LTOT only subjects. Hospital and ICU admission rates between both the treatment and control groups in the two RCTs showed no significant difference (table 13). The data were not combined due to the different unit of measure used in both studies. The bilevel NIPPV groups in each of the RCTs had a reduction in total hospital admissions compared with baseline [11, 23]. CASANOvA et al. [11] reported a $10 \%$ decrease in total hospital admissions at 3 months in the bilevel NIPPV group $(\mathrm{p}<0.05)$, which did not persist at 6 or 12 months. Although CLINI et al. [23] reported a $45 \%$ decrease in total hospital admissions compared with a 3 -yr period leading up to the study, this was not significant 


\begin{tabular}{|c|c|c|c|c|c|}
\hline TABLE 7 & ned analysis for & inspiratory flon & ) in chronic obstru & ¿lmonary c & onrandomised controlled \\
\hline First author [Ref.] & Favours bilevel $n$ & Favours control $n$ & $\mathrm{MD} \pm \mathrm{SE}$ & Weight \% & MD (random) $95 \% \mathrm{Cl}$ \\
\hline AMBRosino [25] & 7 & 7 & $73.0000 \pm 64.1349$ & 22.02 & $73.00(-52.70-198.70)$ \\
\hline Highсоск [18] & 8 & 8 & $149.0000 \pm 222.0434$ & 1.84 & $149.00(-286.20-584.20)$ \\
\hline LIEN [26] & 11 & 11 & $30.0000 \pm 42.6401$ & 49.81 & $30.00(-53.57-113.57)$ \\
\hline Total & 32 & 33 & & 100 & $71.94(12.96-130.92)$ \\
\hline
\end{tabular}

MD: mean difference; $\mathrm{Cl}$ confidence interval. Comparison: crossover trials of bilevel noninvasive positive pressure ventilation versus all modalities. Outcome: $\mathrm{VT} / \mathrm{tl} \mathrm{mL} \cdot \mathrm{s}^{-1}$ Test for heterogeneity: Chi squared $=2.64, \mathrm{df}=3(p<0.45), \mathrm{I}^{2}=0 \%$. Test for overall effect: $Z=2.39(p=0.02)$

and the control group in this 2-yr study actually had an increase in total hospital admissions by $27 \%$. There was a 1 versus 3\% endotracheal intubation/ICU admission rate in the NIPPV versus LTOT group in the study by CASANOvA et al. [11], whereas the study by CLINI et al. [23] showed a 75\% reduction in the bilevel NIPPV group compared with a $20 \%$ increase in the LTOT control group (table 13).

\section{Mortality}

There was no significant reduction in mortality with bilevel NIPPV reported in two RCTs [11, 23].

\section{Comfort/compliance}

The most prevalent complaints were related to asynchrony [25, 27] and sleep [21, 22, 24, 30]. Inability to tolerate pressure-level settings [11, 17], dry nose and/or mouth [24, 30] or mask/ interface intolerance due to problems such as leak or nasal skin lesions/skin breakdown [21, 27] were also reported. Two studies reported bilevel NIPPV intolerance with no reasons cited $[23,29]$.

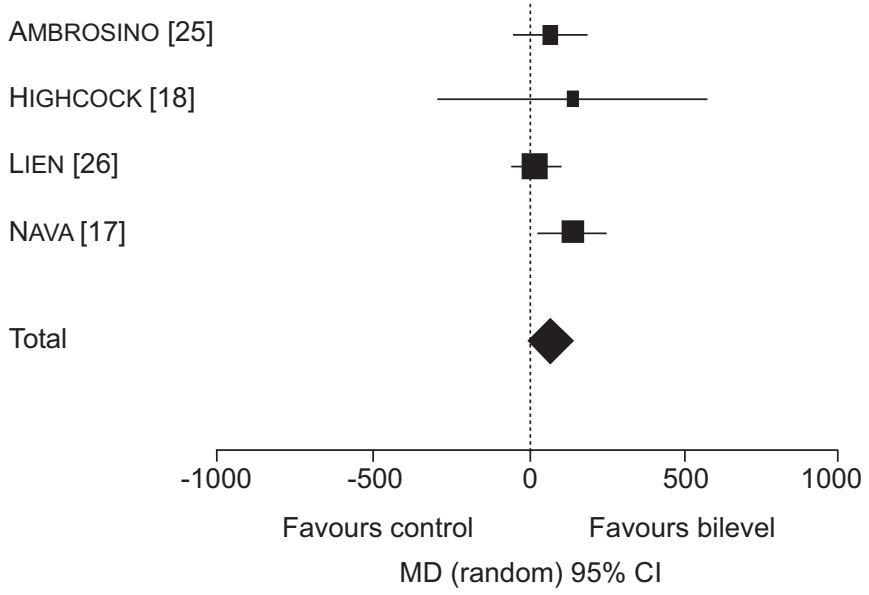

FIGURE 7. Combined analysis for mean inspiratory flow $(\mathrm{V} T / \mathrm{t} t)$ in chronic obstructive pulmonary disease nonrandomised controlled trials. Comparison: crossover trials of bilevel noninvasive positive pressure ventilation versus all modalities. Outcome: $V_{T} / t \mathrm{~mL} \cdot \mathrm{s}^{-1}$. MD: mean difference; $\mathrm{Cl}$ : confidence interval.

\section{DISCUSSION}

\section{Respiratory function}

Although combined analysis of RCTs showed no significant improvement in gas exchange, reduction of hypercapnia was greater in four RCTs [11, 20, 23, 24], which had higher hours of bilevel NIPPV use than in the remaining two RCTs [21, 22]. Consistent reduction of hypercapnia noted on continuous nocturnal monitoring of end-tidal carbon dioxide tension and $P_{\mathrm{tc},} \mathrm{CO}_{2}$ in two non-RCTs by STRUMPF et al. [30] and MEECHAM JONES et al. [29] did not show the same extent of improvement in daytime $\mathrm{Pa}, \mathrm{CO}_{2}$. The extent of reduced hypercapnia, which was greatest in the study by MEECHAM JONES et al. [29], may also suggest that the effectiveness of bilevel NIPPV is greater in COPD patients with a higher baseline $\mathrm{Pa}, \mathrm{CO}_{2}$. Nocturnal $\mathrm{Ptc}_{\mathrm{tc}}, \mathrm{CO}_{2}$ monitoring may be a more dynamic measure of effectiveness of bilevel NIPPV in reduction of hypercapnia in patients with severe stable COPD than arterial blood gases alone.

Within non-RCTs, those which used lower bilevel pressures $[26,27]$ showed less $\mathrm{Pa}_{1} \mathrm{CO}_{2}$ reduction than those that reported greater $\mathrm{Pa}_{\mathrm{a}} \mathrm{CO}_{2}$ reduction with higher pressure levels [17, 20, 25, $28,29]$. Improvements in ventilatory parameters and reduction of PEEPi,dyn reported in one study [17] were proportional to the bilevel NIPPV pressures applied.

Non-RCTs supported a significant improvement in gas exchange (both $\mathrm{Pa}_{2} \mathrm{O}_{2}$ and $\mathrm{Pa}, \mathrm{CO}_{2}$ ) with bilevel NIPPV. Using patients as their own controls may have assisted in controlling for differences in disease severity, as it is likely that in advanced COPD smaller differences in lung function between patients in the treatment and control groups may account for the failure of existing trials to consistently demonstrate improvement in gas exchange with bilevel NIPPV.

Two RCTs that demonstrated improvements in gas exchange reported concurrent improvement in one or more outcome related to ventilatory/breathing pattern [24] and/or respiratory muscle function/work of breathing [19]. Improvements in some flow and volume indices $\left(V^{\prime} \mathrm{E}, V \mathrm{~T}, V \mathrm{~T} / t_{\mathrm{I}}\right)$ in studies that assessed ventilation/breathing pattern were reported with bilevel NIPPV use [17, 18, 24, 27]. Two daytime studies [17, 19] found that the extent of the increase in $V \mathrm{~T}$ was greater with higher bilevel pressures (IPAP/EPAP pressure difference of $\left.1.5 \mathrm{kPa}\left(\geqslant 15 \mathrm{cmH}_{2} \mathrm{O}\right)\right)$, suggesting that the degree of improvement in alveolar ventilation with bilevel NIPPV may be proportional to the IPAP/EPAP pressure difference applied. 


\begin{tabular}{|c|c|c|c|c|c|c|c|}
\hline TABLE 8 & \multicolumn{7}{|c|}{$\begin{array}{l}\text { Combined analysis for maximal inspiratory pressure (MIP) in chronic obstructive pulmonary disease randomised } \\
\text { controlled trials (RCTs) }\end{array}$} \\
\hline \multirow{2}{*}{\multicolumn{2}{|c|}{ First author [Ref.] }} & \multicolumn{2}{|c|}{ Bilevel NIPPV } & \multicolumn{2}{|c|}{ Control } & \multirow[t]{2}{*}{ Weight \% } & \multirow[t]{2}{*}{ WMD (random) $95 \% \mathrm{Cl}$} \\
\hline & & $\mathbf{n}$ & Mean \pm SD & $\mathbf{n}$ & Mean \pm SD & & \\
\hline \multicolumn{2}{|l|}{ CLINI [23] } & 38 & $50.60 \pm 20.60$ & 46 & $48.10 \pm 27.70$ & 77.00 & $2.50(-7.73-12.73)$ \\
\hline \multicolumn{2}{|l|}{ Total } & 47 & & 54 & & 100 & $4.45(-4.52-13.43)$ \\
\hline
\end{tabular}

The latter studies, as well as the study by LIN et al. [27], which was nocturnal and showed less reduction in $V \mathrm{~T}$ and $V^{\prime} \mathrm{E}$ during sleep with NIPPV, despite the use of lower pressures of IPAP $0.78-1.5 \mathrm{kPa}\left(8-15 \mathrm{cmH}_{2} \mathrm{O}\right) / \mathrm{EPAP}<0.20 \mathrm{kPa}\left(<2 \mathrm{cmH}_{2} \mathrm{O}\right)$, suggest an adjunctive role for bilevel NIPPV use in the management of CRF due to severe stable COPD.

Reductions in $V^{\prime} \mathrm{E}$ and/or PEEPi,dyn associated with significant improvements in gas exchange in some studies [17, 19] suggests that improved alveolar ventilation may result in reduced end-expiratory lung volumes and reduced lung hyperinflation in response to bilevel NIPPV use in some individuals with severe stable COPD. DiAz et al. [19] assessed the effect of bilevel versus sham NIPPV on lung hyperinflation in 36 patients with severe stable hypercapnic COPD, and reported significant decreases in mean inspiratory pressure swing, PEEPi,dyn, dynamic lung elastase, inspiratory lung resistance and tension time index, consistent with reduced lung hyperinflation and reduced inspiratory mechanical workload. It may be, then, that a proportion of patients with more hyperinflation (who are at a greater mechanical disadvantage and attempt to avoid fatiguing by reducing their $V \mathrm{~T}$ to spare

\section{CLINI [23]}

RENSTON [22]

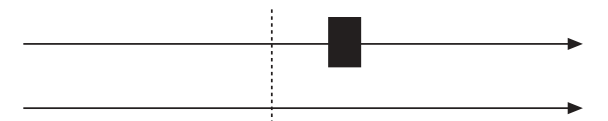

Total

\begin{tabular}{ccccc}
\hline-10 & -5 & 0 & 5 & 10 \\
& Favours control & & Favours bilevel \\
WMD (random) & $95 \% \mathrm{Cl}$ &
\end{tabular}

FIGURE 8. Combined analysis for maximal inspiratory pressure (MIP) in chronic obstructive pulmonary disease randomised controlled trials (RCTs). Comparison: RCT trials of bilevel noninvasive positive pressure ventilation versus all modalities (long-term oxygen therapy, sham ventilation, exercise). Outcome: MIP $\mathrm{cmH}_{2} \mathrm{O}$. WMD: weighted mean difference; $\mathrm{Cl}$ : confidence interval. the workload on their respiratory muscles, resulting in alveolar hypoventilation) constitute a subset that respond more favourably to bilevel NIPPV. This may explain some of the inconsistent findings regarding effectiveness of bilevel NIPPV in severe stable COPD.

Assessment of diaphragmatic muscle activity/work of breathing (electromyogram [24], Pdi [17]) demonstrated reductions, thus favouring bilevel NIPPV for respiratory muscle rest associated with reduced work of breathing. NAVA et al. [17] also showed a proportionately greater reduction in work of breathing with increasing IPAP, to a maximum of $2.0 \mathrm{kPa}$ $\left(20 \mathrm{cmH}_{2} \mathrm{O}\right)$, following the addition of $0.49 \mathrm{kPa}\left(5 \mathrm{cmH}_{2} \mathrm{O}\right)$ $\mathrm{EPAP}$, suggesting greater respiratory muscle rest and reduction of workload proportional to bilevel NIPPV pressures used. LIEN et al. [26] showed a reduction of respiratory accessory muscle work (EMGst) of breathing during bilevel NIPPV use that was greater in patients with an FEV1 $<0.55 \mathrm{~L}$ versus in those with an FEV1 $>0.55 \mathrm{~L}$, which may lend support for a subset of responders who may benefit from bilevel NIPPV to reduce work of breathing.

\section{Health-related outcomes}

A number of studies reported significant improvement in exercise tolerance following regular bilevel NIPPV use, suggesting that periods of regular bilevel NIPPV use (during which the inspiratory mechanical load is relieved allowing respiratory muscle rest) may contribute to improvement in exercise. GARROD et al. [24] found that bilevel NIPPV, when combined with an exercise programme, improved oxygenation and HRQOL in conjunction with exercise tolerance, suggesting the possibility of bilevel NIPPV enhancing the effects of pulmonary rehabilitation. Bilevel NIPPV use during exercise did not improve exercise tolerance. As bilevel NIPPV delivers preset IPAP/EPAP pressure levels, it may not be as responsive as other modes of NIPPV to sudden changes/increased mechanical load and ventilatory and metabolic demand that occur during exercise. This may explain the findings by HiGHCOCK et al. [18], who assessed exercise tolerance during bilevel NIPPV via mouthpiece and showed reduced exercise tolerance on all three types of bilevel NIPPV. Newer NIPPV modes, such as proportional assist ventilation, which deliver flow and volume in proportion to each inspiratory effort, might allow more synchrony than bilevel NIPPV with active exercise. 


\begin{tabular}{|c|c|c|c|c|c|}
\hline TABLE 9 & \multicolumn{5}{|c|}{$\begin{array}{l}\text { Combined analysis for maximal inspiratory and expiratory mouth pressure ( } P \text { I, max and } P \text { E, max, respectively) in chronic } \\
\text { obstructive pulmonary disease nonrandomised controlled trials }\end{array}$} \\
\hline First author [Ref.] & Favours bilevel $n$ & Favours control $n$ & $\mathrm{MD} \pm \mathrm{SE}$ & Weight $\%$ & MD (random) $95 \% \mathrm{Cl}$ \\
\hline \multicolumn{6}{|l|}{$P I$, max analysis } \\
\hline LIEN [26] & 11 & 11 & $0.4000 \pm 12.8142$ & 3.35 & $0.40(-24.72-25.52)$ \\
\hline LIN [27] & 10 & 12 & $5.0000 \pm 2.3839$ & 96.65 & $5.00(0.33-9.67)$ \\
\hline \multicolumn{6}{|l|}{$P E$,max analysis } \\
\hline LIEN [26] & 11 & 11 & $1.0000 \pm 10.3830$ & 4.40 & $1.00(-19.35-21.35)$ \\
\hline LIN [27] & 10 & 12 & $5.0000 \pm 2.2265$ & 95.60 & $5.00(0.64-9.36)$ \\
\hline Total & 21 & 23 & & 100 & $4.82(0.56-9.09)$ \\
\hline
\end{tabular}

MD: mean difference; $\mathrm{Cl}$ confidence interval. Comparison: crossover trials of bilevel noninvasive positive pressure ventilation versus all modalities. Outcome: PI,max $\mathrm{CmH}_{2} \mathrm{O}$ or $P E$, max $\mathrm{cmH}_{2} \mathrm{O}$. Test for heterogeneity in $P$ I,max analysis: Chi squared $=0.12, \mathrm{df}=1 \quad(p<0.72), \mathrm{I}^{2}=0 \%$. Test for overall effect: $Z=2.07$ ( $p=0.04$ ). Test for heterogeneity in $P E$, max analysis: Chi squared $=0.14, d f=1(p<0.71), I^{2}=0 \%$. Test for overall effect: $Z=2.22(p=0.03)$

a)

LIEN [26]

LIN [27]

Total

b)

LIEN [26]

LIN [27]

Total

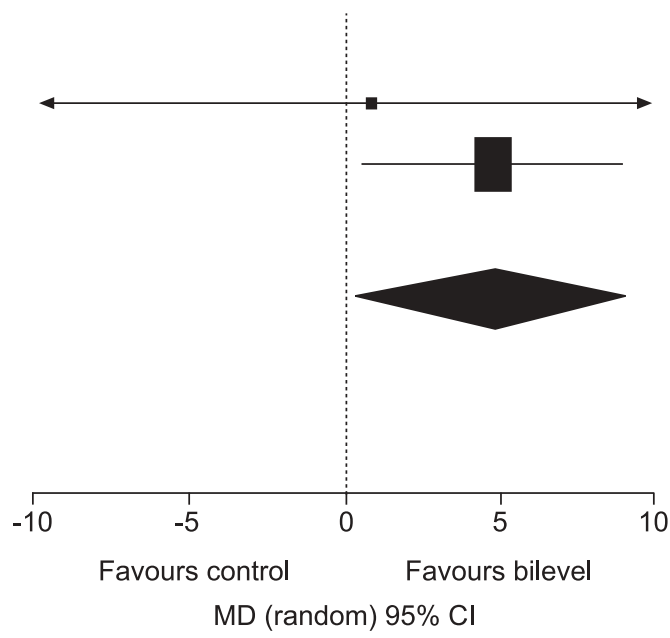

FIGURE 9. a) Combined analysis for maximal inspiratory mouth pressure $(P I, \max )$ in chronic obstructive pulmonary disease nonrandomised controlled trials. Comparison: crossover trials of bilevel noninvasive positive pressure ventilation versus all modalities. Outcome: $\mathrm{Pl}, \max \mathrm{cmH}_{2} \mathrm{O}$. b) Combined analysis for maximal expiratory mouth pressure $(P E, \max )$ in chronic obstructive pulmonary disease nonrandomised controlled trials. Comparison: crossover trials of bilevel noninvasive positive pressure ventilation versus all modalities. Outcome: $P E$, max $\mathrm{cmH}_{2} \mathrm{O}$. MD: mean difference; $\mathrm{Cl}$ : confidence interval.
Significant reduction of dyspnoea associated with bilevel NIPPV use was consistently reported in RCTs [11, 22-24] up to 2 yrs in length. One RCT [24] demonstrated improvement in functional status that was associated with improvement in the four components of the CRDQ scale, including dyspnoea and fatigue. MCCONNELL and ROMER [31] recently described how the impairment of contractile properties of the respiratory muscles, with resultant functional weakening and fatigue brought about by dynamic hyperinflation in COPD, creates worsening dyspnoea intensity and also described the role of respiratory muscle training in reducing the intensity of dyspnoea through improvement of the contractile properties of the respiratory muscles. It may be possible that nocturnal bilevel NIPPV, which reduces factors that have the potential to increase dyspnoea (by improving alveolar ventilation and reducing hyperinflation, and addressing the factors that impair the contractile properties of the respiratory muscles), in addition to an exercise rehabilitation programme, which augments those factors that have the potential to decrease dyspnoea (by addressing factors that improve contractile properties, through respiratory muscle training), are more effective in combination.

Only three studies [23, 24, 29] assessed HRQOL. All three (12 weeks to 2 yrs in duration) showed significant improvement in HRQOL on at least one validated HRQOL measurement scale. Significant improvements in HRQOL total scores in the studies by both GARROD et al. [24] and MEECHAM JONES et al. [29] were reported to be largely due to significant improvements in symptom components of the scores.

Few studies reported morbidity as an outcome, despite the significant expenditure of healthcare monies devoted to treatment of COPD exacerbations. The two studies [11, 23] that assessed morbidity were longer studies (1 and 2 yrs, respectively). Although reductions in hospital admissions between the bilevel NIPPV and LTOT groups in the two RCTs [11, 23] failed to reach significance, reductions in both hospital stay and dyspnoea were associated with reduced frequency of hospital admissions within the bilevel NIPPV groups. Reduction of hospital stay and reduced need for 
TABLE 10 Dyspnoea ratings with bilevel noninvasive positive pressure ventilation use in chronic obstructive pulmonary disease

\begin{tabular}{|c|c|c|c|c|c|}
\hline First author [Ref.] & Scale used & Trial length & Before/after Rx/CL & Outcome data & Comments \\
\hline \multicolumn{6}{|l|}{ RCTs } \\
\hline \multirow[t]{2}{*}{ CASANOVA [11] } & BORG/MRCD & $1 \mathrm{yr}$ & $\mathrm{Rx}$ & $5 \pm 1.63^{*} / 2^{*}$ & \\
\hline & & & $\mathrm{CL}$ & $4 \pm 1.63 / 2$ & \\
\hline \multirow[t]{2}{*}{ CLINI [23] } & $\begin{array}{l}\text { MRCD at } 0 \text { months/ } \\
12 \text { months/24 months }\end{array}$ & 2 yrs & Rx & $\begin{array}{c}3.3 \pm 0.3 / 2.7 \pm 0.8^{\#} / \\
2.3 \pm 0.72\end{array}$ & \\
\hline & & & $\mathrm{CL}$ & $\begin{array}{c}2.7 \pm 0.6 / 3.0 \pm 0.77 / \\
2.9 \pm 0.72\end{array}$ & \\
\hline \multirow[t]{2}{*}{ GARROD [24] } & CRDQ dyspnoea score & 8 weeks & Rx & 13.1 to $18.0^{\star \star \star}$ & Data from the dyspnoea portion of the \\
\hline & & & $\mathrm{CL}$ & 15.1 to 16.8 & CRDQ instrument \\
\hline \multirow[t]{2}{*}{ RENSTON [22] } & BORG & 5 days & $\mathrm{Rx}$ & $2.0 \pm 1.2$ to $0.7 \pm 0.9^{\star \star}$ & \\
\hline & & & $\mathrm{CL}$ & $1.8 \pm 1.13$ to $1.3 \pm 1.13$ & \\
\hline \multicolumn{6}{|l|}{ Non-RCTs } \\
\hline \multirow[t]{2}{*}{ STRUMPF [30] } & Dyspnoea scale of Mahler & 6 months & Before & $0.6 \pm 1.7$ & Functional impairment dyspnoea rating \\
\hline & & & After & $0.3 \pm 1.3$ & \\
\hline
\end{tabular}

Data are presented as mean $\pm \mathrm{SD}$. Rx: treatment; $\mathrm{CL}$ : control; BORG: Borg dyspnoea scale; MRCD: Medical Research Council dyspnoea scale; CRDQ: Chronic Respiratory Disease Questionnaire. ${ }^{*}: p=0.048$ at 12 months; ${ }^{\bullet}: p=0.013$ at 24 months. ${ }^{*} p<0.05 ;{ }^{* *}: p<0.01 ;{ }^{* \star *}: p<0.001$.

intubation and ICU support with bilevel NIPPV use would translate to reduced healthcare expenditures, as has already been demonstrated in the setting of acute respiratory failure due to COPD exacerbation [32]. Due to the progressive nature of COPD, it is not surprising that studies to date, including those in the current study [11, 23], have not demonstrated reduced mortality in response to bilevel NIPPV therapy.

\section{Comfort/compliance issues}

Studies that reported comfort/compliance issues were shorter trials $[11,17]$ with brief acclimatisation periods and high or low bilevel pressure levels, which may have contributed to intolerance due to patient/ventilator asynchrony resulting either from mask leak accompanying higher bilevel pressures, or increased inspiratory efforts/work due to breathing resulting from lower bilevel pressures. This may have also been the case in the four studies [21, 22, 24, 30] that reported sleeprelated difficulty, which also used lower IPAP/EPAP bilevel pressure settings. Studies that reported mask/interface problems $[21,27]$ or patient/ventilator asynchrony $[25,27]$ as the reason for NIPPV intolerance, were either shorter trials or those that had no acclimatisation period. The 3-month study [29] that had the lowest attrition rate due to comfort/ compliance issues (one (5.5\%) out of 18 patients) in the bilevel

TABLE 11 Functional status/activity of daily living in chronic obstructive pulmonary disease with bilevel noninvasive positive pressure ventilation (NIPPV) use

\begin{tabular}{|c|c|c|c|c|c|}
\hline First author [Ref.] & Trial length & Scale & $\mathbf{R x} / \mathrm{CL}$ & Outcome data & Comments \\
\hline \multirow[t]{7}{*}{ GARROD [24] } & 8 weeks & LCADL & & & Compared bilevel NIPPV and exercise with \\
\hline & & Total score & $\mathrm{Rx}$ & 45.4 to $38.7^{\star \star \star}$ & exercise alone. No significant change in \\
\hline & & & $\mathrm{CL}$ & 40.2 to $33.8^{\star \star \star}$ & self-care or domestic score for the NIPPV \\
\hline & & Physical subscore & $R x$ & 6.0 to $4.65^{\star \star \star}$ & group; no significant change in the leisure or \\
\hline & & & $\mathrm{CL}$ & 5.75 to $5.05^{\star}$ & self-care score for the exercise only group \\
\hline & & Leisure subscore & $\mathrm{Rx}$ & 7.47 to $5.82^{\star \star \star}$ & \\
\hline & & & $\mathrm{CL}$ & 6.25 to 5.70 & \\
\hline \multirow[t]{6}{*}{ Renston [22] } & 5 days & Modified MRCD & $\mathrm{Rx}$ & $3.1 \pm 0.4$ to $2.6 \pm 0.5$ & Three different measurement scales used to \\
\hline & & & $\mathrm{CL}$ & $2.9 \pm 0.4$ to $3.3 \pm 0.4$ & assess functional impairment with activities \\
\hline & & Oxygen cost diagram & $\mathrm{Rx}$ & $16.6 \pm 3.7$ to $17.0 \pm 4.0$ & of daily living, associated with dyspnoea \\
\hline & & & $\mathrm{CL}$ & $15.5 \pm 2.4$ to $13.4 \pm 2.0$ & \\
\hline & & BiPAP functional impairment & $\mathrm{Rx}$ & $24.1 \pm 2.0$ to $22.3 \pm 2.1$ & \\
\hline & & scale & $\mathrm{CL}$ & $4.4 \pm 1.5$ to $23.5 \pm 1.9$ & \\
\hline
\end{tabular}

Data are presented as mean \pm SD. Rx: treatment; CL: control; LCADL: London Chest Activity of Daily Living Scale; MRCD: Medical Research Council dyspnoea scale (rates functional impairment associated with dyspnoea: 0-4 corresponds to least to most); BiPAP functional impairment scale: questionnaire that rates dyspnoea (1-3 corresponds to none to severe) for each of 12 activities of daily living. *: $p<0.05 ; * \star *: p<0.001$. 
TABLE 12 Health-related quality of life with bilevel use in chronic obstructive pulmonary disease

\begin{tabular}{|c|c|c|c|c|c|}
\hline First author [Ref.] & Trial length & Questionnaire & $\mathrm{Rx} / \mathrm{CL}$ & Outcome data & Comments \\
\hline \multicolumn{6}{|l|}{ RCTs } \\
\hline \multirow{3}{*}{ CLINI [23] } & & & $\mathrm{CL}$ & $62 \pm 21$ & for improvement in both groups \\
\hline & & SGRQ at 24 months & $\mathrm{Rx}$ & $62.7 \pm 13.3$ & primarily due to improvement in \\
\hline & & & $\mathrm{CL}$ & $59.52 \pm 20.16$ & symptoms \\
\hline \multirow[t]{2}{*}{ GARROD [24] } & 8 weeks & $\mathrm{CDRQ}$ & $\mathrm{Rx}$ & $68.1 \pm 20.9$ to $92.2 \pm 17.0^{* \star \star}$ & CRDQ total score for Bilevel \\
\hline & & & $\mathrm{CL}$ & $73.3 \pm 22.4$ to $85.1 \pm 23.9^{\star}$ & $\begin{array}{l}\text { NIPPV and exercise versus } \\
\text { exercise only groups }\end{array}$ \\
\hline \multicolumn{6}{|l|}{ Non-RCTs } \\
\hline \multirow[t]{2}{*}{ MEECHAM JONES [29] } & 6 months & SGRQ & $\mathrm{Rx}$ & $60 \pm 26.2^{\star \star *}$ & \\
\hline & & & $\mathrm{CL}$ & $70 \pm 18.7$ & \\
\hline
\end{tabular}

Data are presented as mean \pm SD. Rx: treatment; CL: control; RCT: randomised controlled trial; SGRQ: St. George's Respiratory Questionnaire (lower score reflects improvement); MRF-28: Maugeri Foundation Respiratory Failure Questionnaire; CRDQ: Chronic Respiratory Disease Questionnaire; NIPPV: noninvasive positive pressure ventilation. *: $p<0.05 ;{ }^{* \star *}: p<0.001$.

NIPPV group had a two-night bilevel NIPPV in-hospital acclimatisation period, utilised daily diary cards regarding ventilator use and associated problems, and had outpatient clinic follow-up every 4 weeks. It is likely that a period of in-patient acclimatisation, during which patients are closely monitored and problems related to equipment and patient/ mask interface issues can be managed and pressure levels titrated for both comfort and effectiveness, may be beneficial to improving compliance to bilevel NIPPV.

\section{Conclusions}

Patients with severe stable chronic obstructive pulmonary disease who lack the necessary respiratory reserve to respond to minimal increases in ventilatory demand due to their altered lung dynamics are constantly on the verge of respiratory decompensation. Based on this systematic review, bilevel noninvasive positive pressure ventilation use in a select proportion of patients with severe stable chronic obstructive pulmonary disease can improve gas exchange, exercise

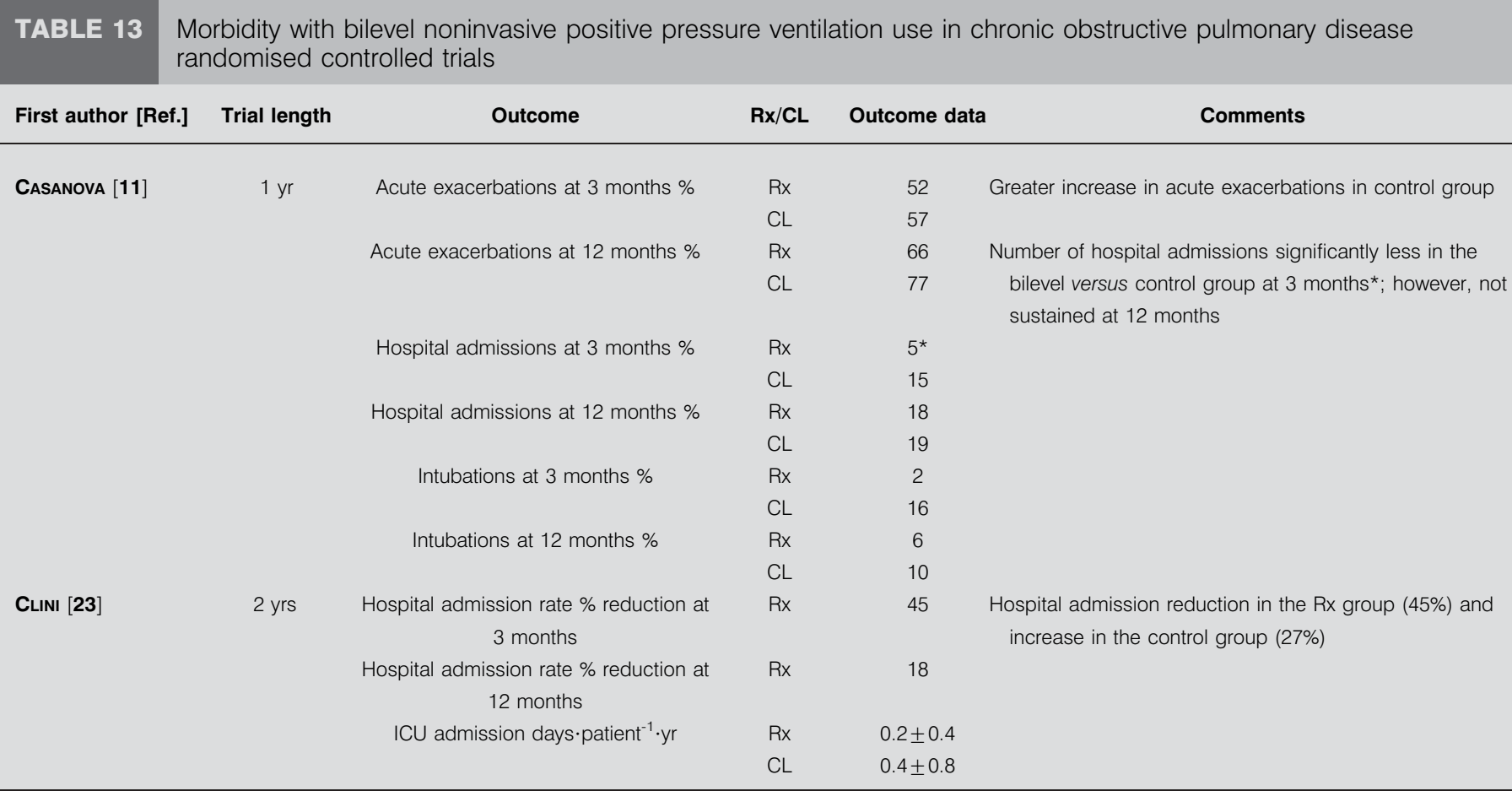

Data are presented as mean $\pm \mathrm{SD}$, unless otherwise stated. Rx: treatment; $\mathrm{CL}$ : control; ICU: intensive care unit. *: $\mathrm{p}<0.05$. 
tolerance, dyspnoea, work of breathing (due to lung hyperinflation), frequency of hospitalisation, health-related quality of life and functional status. This suggests an adjunctive role for the use of bilevel noninvasive positive pressure ventilation in assisting the management of the distressing and debilitating effects of chronic respiratory failure due to chronic obstructive pulmonary disease progression. The effectiveness of bilevel noninvasive positive pressure ventilation used nocturnally and/or as necessary during the daytime is of benefit for intermittent reduction in work of breathing and respiratory muscle rest, which may contribute to improved exercise tolerance on a short-term, day-to-day basis. Lung volumes, alveolar ventilation, and work of breathing are improved during bilevel noninvasive positive pressure ventilation use, but this improvement is not consistently sustained. When assessment of bilevel noninvasive positive pressure ventilation addressed mechanical disadvantage outcomes (inspiratory mechanical load), alveolar hypoventilation, lung hyperinflation, as well as parenchymal changes (alveolar destruction and loss of functioning lung units/airway obstruction) that precede the mechanical disadvantage, bilevel noninvasive positive pressure ventilation has an adjunctive role in the management of chronic respiratory failure in a subset of severe stable chronic obstructive pulmonary disease patients with chronic hypercapnic respiratory failure and increased dynamic intrinsic positive end-expiratory pressure. Inconsistency in the effectiveness of all assessed outcomes may be due to the variability in degree of lung hyperinflation (dynamic intrinsic positive end-expiratory pressure), and bilevel noninvasive positive pressure ventilation levels and duration of use. Nonrandomised controlled trial data found improved gas exchange with bilevel noninvasive positive pressure ventilation, while randomised controlled trial data did not. Lung hyperinflation and work of breathing were reduced in a nonrandomised subset. Dyspnoea, health-related quality of life and morbidity, the least studied outcomes, showed more consistent improvements.

\section{REFERENCES}

1 Ait-Kaled N, Enarson D, Bousquet J. Chronic respiratory diseases in developing countries: the burden and strategies for prevention and management. Bull World Health Organ 2001; 79: 971-979.

2 Anto JM, Vermiere P, Vestbo J, Sunyer J. Epidemiology of chronic obstructive pulmonary disease. Eur Respir J 2001; 17: 982-994.

3 Murray CJL, Lopez AD, eds. The Global Burden of Disease: A Comprehensive Assessment of Mortality and Disability from Diseases, Injuries and Risk Factors in 1990 and Projected to 2020. Cambridge, Harvard University Press, for the WHO and the World Bank, 1996.

4 Standards for the diagnosis and care of patients with chronic obstructive pulmonary disease. American Thoracic Society. Am J Respir Crit Care Med 1995; 152: S77-S121.

5 McNicholas WT. Impact of sleep in respiratory failure. Eur Respir J 1997; 10: 920-933.

6 Murata GH, Kapsner CO, Lium DJ, Busby HK. Time course of respiratory decompensation in chronic obstructive pulmonary disease: a prospective, double-blind study of peak flow changes prior to emergency department visits. Respir Med 1998; 92: 936-941.

7 Clark HE, Wilcox PG. Noninvasive positive pressure ventilation in acute respiratory failure of chronic obstructive pulmonary disease. Lung 1997; 175: 143-154.

8 British Thoracic Society Standards of Care Committee. Non-invasive ventilation in acute respiratory failure. Thorax 2002; 57: 192-211.

9 Meduri GU. Noninvasive positive pressure ventilation in patients with acute respiratory failure. Clin Chest Med 1996; 17: 513-553.

10 Meyer TJ, Hill HS. Noninvasive positive pressure to treat respiratory failure. Ann Intern Med 1994; 120: 760-770.

11 Casanova C, Celli BR, Tost L, et al. Long-term controlled trial of nocturnal nasal positive pressure ventilation in patients with severe COPD. Chest 2000; 118: 1582-1590.

12 Hill NS. Noninvasive ventilation has been shown to be ineffective in stable COPD. Am J Respir Crit Care Med 2000; 161: 689-690.

13 Rossi A. Noninvasive ventilation has not been shown to be ineffective in stable COPD. Am J Respir Crit Care Med 2000; 161: 688-689.

14 Mehta S, Hill NS. Noninvasive ventilation. Am J Respir Crit Care Med 2001; 162: 540-577.

15 Wijkstra PJ, Lacasse Y, Guyatt GH, Goldstein RS. Nocturnal non-invasive positive pressure ventilation for stable chronic obstructive pulmonary disease. Cochrane Database Syst Rev 2002; 3: CD002878.

16 Estabrooks CA, Goel V, Thiel E, et al. Consumer decision aids: where do we stand? A systematic review of structured consumer decision aids 2002. Technical Report, Pub. No. 00-01-TR. Toronto, Institute for Clinical Evaluative Sciences, 2002.

17 Nava S, Ambrosino N, Rubini F, et al. Effect of nasal pressure support ventilation and external PEEP on diaphragmatic activity in patients with severe stable COPD. Chest 1993; 103: 143-150.

18 Highcock MP, Shneerson JM, Smith IE. Increased ventilation with NiIPPV does not necessarily improve exercise capacity in COPD. Eur Respir J 2003; 22: 100-105.

19 Diaz O, Begin P, Torrealba B, Jover E, Lisboa C. Effects of noninvasive ventilation on lung hyperinflation in stable hypercapnic COPD. Eur Respir J 2002; 20: 1490-1498.

20 Krachman SL, Quaranta AJ, Berger TJ, Criner GJ. Effects of noninvasive positive pressure ventilation on gas exchange and sleep in COPD patients. Chest 1997; 112: 623-628.

21 Gay PC, Hubmayr RD, Stroetz RW. Effectiveness of nocturnal nasal ventilation in stable, severe chronic obstructive pulmonary disease during a 3-month controlled trial. Mayo Clin Proc 1996; 71: 533-542.

22 Renston JP, DiMarco AF, Supinski GS. Respiratory muscle rest using nasal BiPAP ventilation in patients with stable severe COPD. Chest 1994; 105: 1053-1060.

23 Clini E, Sturani C, Rossi A, et al. The Italian multicentre study on noninvasive ventilation in chronic obstructive pulmonary disease patients. Eur Respir J 2002; 20: 529-538.

24 Garrod R, Mikelsons C, Paul EA, Wedzicha JA. Randomized controlled trial of domiciliary noninvasive positive pressure ventilation and physical training in severe chronic obstructive pulmonary disease. Am J Respir Crit Care Med 2000; 162: 1335-1341. 
25 Ambrosino N, Nava S, Bertone P, Fracchia C, Rampulla C. Physiological evaluation of pressure support ventilation by nasal mask in patients with stable COPD. Chest 1992; 101: 385-391.

26 Lien TC, Wang JH, Chang MT, Kuo CD. Comparison of BiPAP nasal ventilation and ventilation via iron lung in severe stable COPD. Chest 1993; 104: 460-466.

27 Lin CC. Comparison between nocturnal nasal positive pressure ventilation combined with oxygen therapy and oxygen monotherapy in patients with severe COPD. Am J Respir Crit Care Med 1996; 154: 353-358.

28 Marangoni S, Vitacca M, Quadri A, Schena M, Clini E. Non-invasive haemodynamic effects of two nasal positive pressure ventilation modalities in stable chronic obstructive lung disease patients. Respiration 1997; 64: 138-144.
29 Meecham Jones DJ, Paul EA, Jones PW, Wedzicha JA. Nasal pressure support ventilation plus oxygen compared with oxygen therapy alone in hypercapnic COPD. Am J Respir Crit Care Med 1995; 152: 538-544.

30 Strumpf DA, Millman RP, Carlisle CC, et al. Nocturnal positive-pressure ventilation via nasal mask in patients with severe chronic obstructive pulmonary disease. Am Rev Respir Dis 1991; 144: 1234-1239.

31 McConnell AK, Romer LM. Dyspnea in health and obstructive pulmonary disease. Sports Med 2004; 34: 117-332.

32 Lightowler JV, Wedzicha JA, Elliott MW, Ram FS. Noninvasive positive pressure ventilation to treat respiratory failure resulting from exacerbations of chronic obstructive pulmonary disease: Cochrane systematic review and metaanalysis. BMJ 2003; 326: 185. 